\title{
Cartografías muiskanobas: la apropiación social del territorio desde la propuesta de innovación pedagógica del colegio "Bachillerato técnico Comercial Santa Ana", ubicado en el Municipio de Suacha, Colombia ${ }^{1}$
}

\author{
Muiskanobas cartographies: the social appropriation of the territory from \\ the pedagogical innovation proposal of the school "Bachillerato tecnico \\ Comercial Santa Ana", located in the Municipality of Suacha, Colombia
}

\section{Mapeamiento Muiskanobas: a apropriação social do território a partir da proposta de inovação pedagógica da escola "Bachillerato Técnico Comercial Santa Ana", situado no Município de Suacha, Colômbia}

\author{
Carolina Salcedo², Angie Garzón ${ }^{3}$, Vanessa Muñoz ${ }^{4}$, Miguel Guerrero ${ }^{5}$ y Angélica \\ Acevedo $^{6}$ \\ Colegio Bachillerato Tecnico Comercial Santa Ana
}

\begin{abstract}
RESUMEN
El presente artículo tiene como fin reflexionar sobre la experiencia de innovación pedagógica muiskanoba, que tiene como ejes educar y vivir, en relación a la categoría de producción del espacio social. La metodología implementada es, principalmente, el paradigma cualitativo. Tomamos como referente la IA, investigación-aprendizaje (Panqueba \& Huérfano, 2006), que está fundamentada en el reconocimiento de los y las estudiantes como principales actores del proceso pedagógico y de los docentes como sabedores que guían y co-aprehenden el proceso de enseñanza-aprehendizaje. Esta experiencia se ha desarrollado en el colegio "Bachillerato Técnico Comercial Santa Ana" durante los años 2019 y 2020, aunque es necesario mencionar que la propuesta educativa lleva implementada en la institución desde el año 2002. Un aspecto principal que queremos poner en diálogo es la construcción de identidad territorial ancestral en el municipio: evidenciamos el arraigo cultural y la sensibilización ambiental como necesidades fundamentales para fortalecer las memorias cotidianas del territorio.
\end{abstract}

\footnotetext{
1 Esta Investigación ha sido autofinanciada como esfuerzo de los maestros participantes. Agradecemos al Lic. Freddy Pareja y a la comunidad educativa Santa Ana por la colaboración en este proceso.

2 Licenciada en básica primaria con énfasis en ciencias naturales y educación ambiental, maestrante en innovación social para la educación de la Universidad Minuto de Dios- Bogotá, asesora académica y rectora del colegio Bachillerato Técnico Comercial Santa Ana. E-mail: rectoriamuiskanobasantana@gmail.com. Código ORCID: 0000-0001-9799-7043 3 Licenciada en Humanidades y Lengua Castellana de la Universidad Distrital, docente de español en el Colegio Santa Ana. E-mail: angk1970@gmail.com

4 Socióloga de la Universidad Cooperativa de Colombia, especialista en Derechos humanos y estudios feministas y de género, docente de Ciencias sociales en el Colegio Santa Ana y educadora popular feminista de los colectivos Tejiendo Territorios y Chie- Resistencia Feminista. E-mail: jmunozmo@unal.edu.co. Código ORCID: 0000-0002-7168-1005

5 Sociólogo de la Universidad Nacional de Colombia, docente de Filosofía y economía del Colegio Santa Ana, maestrante en Derechos humanos de la UPTC. E-mail: miguelangelg093@gmail.com. Código ORCID: 0000-0002-5523-0095 6 Licenciada en biología de la Universidad Distrital Francisco José de Caldas, docente de biología y Medio ambiente en el Colegio Santa Ana. E-mails: maacevedog@correo.udistrital.edu.co - angelicacevedog@hotmail.com. Código ORCID: 0000-0002-0377-9668
}

Recibido:03/04/2020 - Aceptado: 03/05/2020 - Publicado: 28/08/2020

Citar como:

Salcedo, C., Garzón, A., Muñoz, V., Guerrero, M. \& Acevedo, A. (2020). Cartografías muiskanobas: la apropiación social del territorio desde la propuesta de innovación pedagógica del colegio "Bachillerato técnico Comercial Santa Ana", ubicado en el Municipio de Suacha, Colombia. Espiral, revista de geografías y ciencias sociales, 2(3), 015 - 034. http://dx.doi.org/10.15381/ espiral.v2i3.17668

C Los autores. Este artículo es publicado por Espiral, revista de geografías y ciencias sociales de la Universidad Nacional Mayor de San Marcos. Este es un artículo de acceso abierto, distribuido bajo los términos de la licencia Creative Commons Atribucion - No Comercia_Compartir Igual 4.0 Internacional. (http://creativecommons.org/licenses/by-nc-sa/4.0/) que permite el uso no comercial, distribución y reproducción en cualquier medio, siempre que la obra original sea debidamente citada. 


\begin{abstract}
The purpose of this article is to reflect on the Muiskanoba pedagogical innovation experience, which has education and living as its axes, in relation to the production category of the social space. The implemented methodology is, mainly, the qualitative paradigm. We take as a reference the Al, researchlearning (Panqueba \& Huérfano, 2006), which is based on the recognition of the students as main actors in the pedagogical process and of the teachers as knowledges who guide and co-apprehend the teaching process -learning. This experience has been developed in the school "Bachillerato Técnico Comercial Santa Ana" during the years 2019 and 2020, although it is necessary that the educational proposal has been implemented in the institution since 2002. A main aspect that we want to put into dialogue is the construction of ancestral territorial identity in the municipality: we demonstrate cultural roots and environmental awareness as fundamental needs to strengthen the daily memories of the territory.
\end{abstract}

\title{
RESUMO
}

O objetivo deste artigo é refletir sobre a experiência de inovação pedagógica Muiskanoba, cujos eixos são educar e viver em relação à categoria de produção do espaço social. A metodologia implementada é, principalmente, o paradigma qualitativo. Temos como referência a pesquisa-aprendizagem (Panqueba \& Huérfano, 2006), que é baseado no reconhecimento dos alunos como atores principais do processo pedagógico e dos professores como sabedores (conhecedores) que orientam e também aprendem do processo de ensina-aprendizagem. Esta experiência foi desenvolvida no colégio "Bachillerato Tècnico Comercial Santa Ana", durante os anos de 2019 e 2020, embora seja necessário referir que a proposta pedagógica está implementada na instituição desde o 2002. Um principal aspecto que queremos colocar em diálogo é a construção da identidade territorial ancestral no município: nós evidenciamos as raízes culturais e a consciência de meio ambiente como necessidades fundamentais para fortalecer a memória do dia a dia do território.

PALABRAS CLAVE: Pedagogías interculturales; muiskanoba; decolonialidad del saber; cartografías sociales; Suacha; apropiación social del territorio.

KEYWORDS: Intercultural pedagogies; muiskanoba; decoloniality of knowledge; social cartography; Suacha; social appropriation of the territory.

PALAVRAS-CHAVE: Pedagogias Interculturais; muiskanoba; descolonialidade do saber; mapeamento sociais; Suacha; apropriação social do território.

\section{Introducción}

La educación básica y media en Colombia presenta múltiples problemáticas en relación a la pertinencia de los contenidos, las actividades, las temáticas plasmadas en el currículo educativo y la finalidad misma de la educación para la construcción de un proyecto de vida. Esto puede evidenciarse en muchos aspectos dentro del proceso escolar. Un ejemplo de ello son las labores que los estudiantes desarrollan al culminar la educación básica secundaria. En un territorio como Suacha, donde las oportunidades de acceder a la educación superior son limitadas ya que muchas familias no poseen recursos para pagar una educación superior en instituciones privadas, gran parte de los recién egresados divagan entre pocas posibilidades: intentar acceder a instituciones públicas de educación superior, donde los cupos no satisfacen en absoluto la demanda; laborar por un bajo salario en trabajos inestables; quedarse en casa bajo el abrigo de los padres, quienes mantienen el hogar.

Es así como el aula de clase, donde se reúnen diversos contextos y culturas, se convierte en una muestra pequeña de lo que es la sociedad. Esta multiplicidad nos muestra las diferentes necesidades académicas y sociales de cada uno de los niños que tejen a diario en los espacios escolares, necesidades que se ven apaciguadas por el afán de acogerse a la generalidad en los currículos y estándares (que no apuntan a una educación situada). De esta carrera temática llegan a la meta estudiantes agotados, 
saturados y, sobretodo, cuyos contextos culturales ancestrales se han perdido, ya que son poco visualizados durante el tiempo que corrieron en las dinámicas del colegio.

Entonces esta capacidad de poner en diálogo los contextos de sus estudiantes y articularlos a los objetivos de la enseñanza. Puesto que los procesos que se viven se desarrollan desconectados de cada una de las realidades de las comunidades, del concepto de necesidad individual y del reconocimiento del propio territorio. Esto tiene como consecuencia una falta de reconocimiento de la raíz que llevamos dentro y que hemos escondido con tierras ajenas. Todo esto es como esa hilera de nudos cargados de situaciones donde nos vemos obligados como maestros y sabedores a seguir un sistema, un "orden" ideal de las cosas, programado por los currículos, lúdicas y didácticas eurocentradas. Nos vemos obligados a olvidar sentir, confluir y descubrir al otro, acciones que llevarían a cada uno a descubrirse a sí mismo, en su interior, a reencontrarse con el legado indígena de su territorio.

La falta de descubrir lo que el territorio mismo ha tejido en cada uno de los que confluyen en las escuelas y planteles educativos a diario se ve reflejada en el caso del municipio de Suacha, un territorio que necesita ser descubierto, valorado y amado. Es necesario tomarnos el tiempo, como mediadores en el aula, de ver esas raíces que traen consigo los estudiantes. Son raíces que tienen en ellos desde que son gestados, llevan los territorios en ellos mismos desde que pusieron los pies en la tierra por primera vez.

Desde la propuesta deinnovación pedagógica se entienden las aulas como un fragmento de la realidad social, ellos nos permite pensamos la apropiación del territorio como un requerimiento fundamental para interiorizar la pedagogía muiskanoba, desde el tejido, la palabra y el recorrer el territorio para su transformación y el encuentro con la ancestralidad muisca propia del municipio. Muiskanoba es una propuesta de investigación-aprehendizaje en constante siembra, dibujada en el territorio del pueblo Muisca y aprehendida de abuelas y abuelos que legaron sus saberes y conocimientos por medio de las palabras, grafías, pictogramas, juegos, costumbres y prácticas de vida cotidiana. Igualmente ha sido un proceso de reowayabtyba (esta es una palabra del vocablo muisca que significa "volver a sembrar").

Desde estas nociones, la pregunta de investigación que guía el presente texto es: ¿cómo se construye y se vive la noción de territorio en el "colegio Bachillerato tecnico comercial Santa Ana" desde su propuesta de innovación pedagógica muiskanoba? Las reflexiones que suscita este cuestionamiento nos permite hablar de aspectos enfocados en el espacio.

Desarrollamos este siguiente artículo exponiendo en primera medida la propuesta de innovación pedagógica muiskanoba, la cual es nuestro hilo conductor para realizar la práctica pedagógica docente. Esta se fundamenta en el reconocimiento de los saberes ancestrales en el territorio Suachuno ${ }^{7}$, desde los territorios de aprehendizaje ${ }^{8}$ muiskanoba.

En segundo lugar, se hace referencia a las diferentes nociones teóricas que han analizado la apropiación de territorio como una necesidad latente. En tercero, se realiza un diálogo acerca de la noción de cartografías de la precariedad, donde se quiere problematizar dicha noción desde una perspectiva decolonial, antipatriarcal y anticapitalista. Esto lleva a plantear postulados teóricos desde los que se proponen las cartografías de la resistencia, que se construyen en diferentes espacios sociales. Finalmente, se abordan reflexiones que invitan a generar prácticas adentro y afuera de las aulas para tejer como común-unidad.

7 Suacha es un municipio que tiene una riqueza arqueológica importante, que se ha visibilizado más a partir del esfuerzo de diferentes instituciones (por ejemplo, con el Instituto Colombiano de Antropología e Historia -ICANH).

$8 \mathrm{El}$ concepto territorios de aprehendizaje hace referencia a los temas y contenidos que desde la experiencia toman relevancia en la vida de las personas porque significan aspectos de la vida cotidiana, de la ciencia, de la historia o de las memorias que construyen y aportan a los saberes colectivos. 


\section{Propuesta de innovación pedagógica Muiskanoba}

"Para mí muiskanoba es un novedoso sistema de aprendizaje que busca explicar los orígenes y los porqués de las cosas, partiendo de los saberes de nuestros ancestros. Es una nueva cultura, un modelo de vida que nos inspira a estar en paz y en armonía en nuestro ambiente".

Laura Pachón, grado séptimo $(2020)^{9}$

La propuesta de innovación pedagógica muiskanoba surgió en el colegio "Bachillerato Tecnico Comercial Santa Ana" hace 18 años. La motivación de su surgimiento fue saber más sobre las riquezas pictográficas y arqueológicas, así como sobre las cosmovisiones muiscas del municipio. Aspectos que fueron de vital interés para el cofundador del colegio, Freddy Alfonso Pareja Pesca. Él, como por una cita con el destino, se encontró con dos personas inquietas por la innovación académica: Arturo Huérfano y Jairziño Panqueva, con quienes mediante horas de especulación académica empiezan a dar forma a la pedagogía institucional, cambiando de paradigma pedagógico y buscando el coexistir intercultural en el aula.

\section{Territorios de aprendizaje desde la pedagogía Muiskanoba}

Para iniciar los diálogos la primera pregunta que nos hacemos es “iqué significa muiskanoba?":

Muiskanoba es una propuesta de investigación-aprehendizaje descubierta en territorio del pueblo Muisca y aprehendida de abuelas y abuelos que legaron sus saberes y conocimientos por medio de las palabras, grafías, pictogramas, juegos, costumbres y prácticas de vida cotidiana. Igualmente ha sido un proceso de reowayabtyba donde niñas y niños, jóvenes y gente adulta, han colocado sus deseos, pensamientos y costumbres. Desde su origen étnicoindígena- rural- urbano Muiskanoba se proyecta hacia la población habitante actual de la sabana de Bogotá, con la finalidad de llevarlos a aprehender las diversas formas de vivir el Territori. (Panqueba, 2006).

Esta propuesta contempla que el aprendizaje es fruto de la cotidianidad y la interculturalidad. Donde cada comunidad simboliza diversos territorios que cuentan con sus propias ideas, que dan razón a su existencia. Éstas se pierden cuando, de forma externa, se les aplican categorías centrales que pretenden institucionalizar y universalizar sus prácticas, tal como lo señala Panqueba (2006). De esta forma, el concepto territorio cobra un nuevo significado, que trasciende más allá del espacio, donde el ser es también un territorio, definido por las interacciones sociales y culturales con un espacio definido. Panqueba y Huerfano (2006) afirman que las "territorialidades son generadoras de arraigos que se pueden describir como identificaciones o identidades culturales".

Dentro de ese diálogo de saberes con los abuelos Muiscas, con los niños, niñas y jóvenes, se postulan seis estrategias pedagógicas para abordar el conocimiento, las cuales se describen de la siguiente manera (Panqueba y Huérfano, 2006):

- Pedagogía de la contemplación: Consiste en el ritual de ver y observar. Por una parte, la contemplación se remite a un ritual del Rikuna (ver o mirar en lengua Kichwa), es leer la cotidianidad con la mirada del inicio o primera impresión, con lo espontáneo y sin pre-juicios, pre-conceptos ni procedimientos. Por otra parte, encaminado al objetivo de contemplar, tenemos el ritual del Ricunayana (mirar con atención en lengua kichwa), el cual consiste en observar con minucia, con un objetivo y de manera planeada y con un procedimiento cotidiano. La pedagogía de la contemplación es la observación, es la vida y el sentir de la gente. Contemplar es interpretar la vida desde los ojos que la ven.

9 Los aportes de las estudiantes se transcriben de manera literal, con el fin de mantener su escritura y forma de comunicarse. 
- Pedagogía de las memorias cotidianas: Es captar la vida diaria, la realidad, con ayuda de herramientas como la escritura, el dibujo, los medios electrónicos, la fotografía, el video y el audio, es acercarse a otras formas de conocer, que se encuentran presentes en las formas que visualizamos diariamente y que por los momentos de celeridad modernos no disfrutamos, compartimos o expresamos de manera sencilla, sin embargo los niños y niñas nos lo recuerdan a diario con su creatividad y espontaneidad.

- Pedagogía de la revisión histórica: Los documentos producidos y reproducidos por la hegemonía y por la disidencia han de ser revisados, recuperados y estudiados para conocerlos y ubicar la identificación y las identidades que históricamente han sido asignadas desde poderes ajenos a las diversas culturas. Revisar estas historias conlleva al aprehendizaje de saberes oficiales, institucionales e institucionalizados, pues contienen memorias cotidianas de escenas y escenarios de los cuales no hemos hallado información en los territorios. En referencia a las identidades, tenemos que estas han estado dadas por agentes externos a las comunidades y sus prácticas.

- Pedagogía de la descripción: A través de manifestaciones visuales, escritas, sonoras, corporales, gastronómicas, religiosas y gráficas, se aprehenden y crean los conocimientos y saberes contemplados en la cotidianidad. Esta pedagogía se ha constituido como la metodología para la propuesta pedagógica de Muiskanoba. La descripción ayuda a pensar las relaciones interculturales, desde los estudios étnicos, rurales, urbanos, culturales y, en general, desde todos los campos aplicables a este ámbito.

- Pedagogía de las cuencas de los descubrimientos: El juego cromático y el lenguaje visual, evidenciados en su máxima expresión en los pictogramas, nos han comunicado las formas de ver y sentir la cotidianidad de quienes dejaron esos escritos, de allí hemos aprehendido a contemplar y describir.

- Pedagogía de las confluencias: Desde las pretensiones por reproducir, reinterpretar y crear con lenguajes adquiridos en los aprehendizajes obtenidos del territorio muisca, hemos confluido en prácticas artísticas y artesanales, guiados por el patrimonio visual muisca. En este sentido, hemos itinerado principalmente por arte lítico, rupestre, cerámico, textil y orfebre.

Como mencionan Panqueba y Huérfano (2006) cada una de estas pedagogías han permitido construir y recorrer los territorios ancestrales, partiendo de que todos somos un primer territorio, llenos de experiencias, vivencias, contemplaciones y diferentes maneras de describir nuestros sentires, lo que permite un ejercicio de aprehendizajes desde los territorios ajenos.

Las personas conformamos territorio en la medida de nuestras relaciones y también los territorios conforman nuestro ser como personas. Los territorios son localizaciones recorridas por diferencias, que constantemente se movilizan al interior de los mismos y también hacia sus exteriores. Somos territorios, pero también los otros y las otras gentes y tierras lo son. Las personas que habitamos territorios somos a la vez territorios más pequeños.

\section{Tejidos Interculturales}

Partiendo de los territorios que cada uno tiene, es necesario reconocer que desde antes de seres humanos, ya como mamíferos, se ha recorrido una historia con un hilo, el cual sería una memoria que se guarda en nuestras bases genéticas y que provee una esencia interna que está llena de diversidades y que, con el crecimiento de la humanidad, se ha ido enriqueciendo en sentires, emociones, texturas, colores. Como 
menciona Ortiz (2019), es un proceso natural que configuramos, donde se entreteje la cultura, los conocimientos y el espíritu con los otros, co-existe una historia personal con una social.

Por otro lado, dentro de nuestro contexto, Suacha es un territorio muisca. Está lleno de historias y contenido ancestral. Sin embargo, en nuestros días es un territorio que recoge diversidades culturales ya que es un punto estratégicamente cercano a Bogotá, donde llegan y encuentran cobijo diferentes comunidades, tanto de nuestro espacio nacional como incluso internacional. Todas estas personas vienen cargadas de hilos que los mantienen unidos a sus raíces y, así al llegar a nuestro territorio, entrelazan y tejen nuevos territorios en diferentes espacios. Uno de estos territorios es el académico, donde niños, niñas y jóvenes que continúan con sus procesos educativos, posicionándose en los espacios de sabiduría, ofrecidos por el municipio, que se construyen de la mano con comunidad muiskanoba. Uno de estos espacios es el Colegio "Bachillerato Técnico Santa Ana", donde muchos de los estudiantes encuentran la libertad de expresarse, de tejer de manera más auténtica sus sentires y los saberes ancestrales de su territorio. La historia que hay detrás de cada persona, al enfrentarse a espacios como estos donde prevalece el confluir, genera la tranquilidad de poder expresarse y describir sus realidades con los demás miembros de la comunidad, tanto con compañeros, como con sabedores y familias.

Dentro de nuestra filosofía y de nuestro andar hemos planteado el uso de las diferentes maneras de expresarnos para tejer multiculturalidad, apoyándonos en los proyectos artísticos y ambientales, los cuales permiten ir más allá de la etapa escolar de los estudiantes ya resultan bases sólidas para la vida después del paso por el colegio. Esto se sustenta en que actualmente las interculturalidades son un tema transversal desde el paradigma de los enfoques diferenciales, lo cual ha originado multiplicidad de emprendimientos interdisciplinares. Algunas experiencias maduradas son referentes para superar los discursos multiculturales y los paradigmas críticos cargados de símbolos, proponiendo acciones alternas con respecto a las desigualdades históricas, en este sentido sobresalen los proyectos emprendidos desde las artes, ya que desde allí se dan reflexiones en torno al tema ambiental (Cuervo, 2014, pp. 141-151).

\section{La noción de territorio y la resignificación de lo ancestral}

“...lo que me dice mi mamá que recuerda de mi barrio, antes que hubieran casas, es que antes estaba lleno de árboles y todo estaba más limpio, al pasar de los tiempos empezaron a construir la casas y empezaron a haber muchos escombros"

Laura Pachón, estudiante de séptimo, 2020

En la historia de América Latina existe una lucha permanente por superar los obstáculos de carácter político, económico, cultural y social que no han permitido la plena realización de los derechos. De ahí que diversos sectores, grupos, clases y etnias, han debido librar luchas o configurar experiencias e innovaciones sociales con el objetivo no solo de conquistar derechos sino de resignificar el territorio social (Timm, 2017; Cocha, 2007; Rodríguez Salgado, 2001). De esa forma, y desde un punto de vista decolonial, la lucha por los derechos y la resignificación del territorio, en la cual lo local emerge como contraposición a aquellos factores globales que suprimen los derechos tal y como lo es el capitalismo más voraz, implica la aparición de movimientos sociales antihegemónicos e incluso de imaginarios étnicos que en su momento fueron opacados por la modernidad y que ahora vuelven a emerger, llegando a ser parte, recientemente, de los mecanismos legales (Acosta, 2015). De hecho, se podría decir que la defensa y apropiación del territorio va de la mano con los procesos sociales y culturales, para establecer innovaciones en los modelos pedagógicos, tal y como lo es el modelo de innovación muiskanoba que se reseña en este artículo. 
Hay que tener en cuenta que las visiones culturales existen con las prácticas y estas, de acuerdo con autores como Enríquez (2007) y Stoller (2009), suelen cambiar y actualizarse constantemente tanto en los aspectos técnicos como en los sociales. Pues bien, las prácticas requieren a su vez un espacio vital, es decir, un territorio (Hinestroza y Guerrero, 2017). Un grupo social dado no puede ser y expresarse como tal si no cuenta con un territorio para vivir, según lo que se piensa y se desea como forma de vida. Partiendo de ahí, para muchas comunidades del país, que aún mantienen una visión ancestral o que desean rescatar las raíces de pueblo autóctonos, la visión de territorio que tienen es generalmente entendida como el espacio donde las personas o los integrantes de la comunidad desarrollan colectivamente su ser en armonía con la naturaleza (Hinestroza y Guerrero, 2017).

En otras palabras, las visiones autóctonas del territorio pueden llegar no solo a concebir otras formas de relacionamiento social, sino de relación con la misma naturaleza. No es de extrañar que estas visiones planeen para la vida, mientras que en el modelo estandarizado de desarrollo del moderno mundo industrial se ordene el territorio pensando solo en el crecimiento económico e innovando en la educación al servicio del mercantilismo dentro del sistema capitalista (Dussel, 2014).

De esa forma, planear para la vida implica mantener el entorno territorial como un lugar digno de la comunidad en general, con las condiciones básicas de bienestar. Además, una organización que luche por la conservación del territorio, tanto en el aspecto físico como en las prácticas sociales, y que se esfuerce para llevar a cabalidad su tarea en función de los derechos colectivos y la herencia de los ancestros, en relación con el nuevo paradigma latinoamericano transmoderno: el buen vivir.

En este sentido, desde el aula se apela a la noción de El cuerpo como territorio donde planteamos que el primer escenario de reconocimiento mutuo es el cuerpo, entendiéndolo como una dimensión externa de la madre naturaleza que se exterioriza por medio de nuestro ser/sentir. El reconocimiento de nuestros cuerpos nos invita a explorar procesos desde la sexualidad, la autoestima, la autovaloración y el tejido propio.

Tal como lo menciona Yerin Mendoza (2003), desde la perspectiva teórica de David Harvey (2003), el cuerpo se concibe como la medida de todas las cosas, es un campo de conocimiento con una tradición filosófica amplia que cobra mayor interés en los debates contemporáneos de género, sexualidad y poder (Mendoza, 2003,pág.10). Darle relevancia al cuerpo implica reconocer la categoría subjetiva de los relacionamientos sociales de los estudiantes y nos exige a los maestros abordar la sexualidad desde una perspectiva integral.

Harvey plantea una forma dialéctica de acceder a este tema, a partir de la "teoría del sujeto corporal de Marx" (ibíd.), la cual pone en conexión los procesos histórica y geográficamente diversificados con la dimensión activa del individuo, su relación porosa con el entorno, el otro y la naturaleza (Harvey, 2003). Desde esta mirada de Harvey, se nos invita a resignificar los espacios sociales, en donde convergemos como sujetos y a la vez en donde el cuerpo toma una especial relevancia como origen de subordinación pero también como una herramienta capaz de expresar las luchas sociales que se gestan en los territorios personales y colectivos. Una clara muestra de ello es el papel de las comunidades indígenas que expresan desde su cosmogonía aspectos de su corporalidad y su identidad que nos interpelan como sujetos sociales. Otro ejemplo, son las luchas de las mujeres negras que han combatido las cadenas del racismo en diferentes horizontes políticos y cotidianos. Desde el aula priorizamos la concepción del cuerpo como herramienta emancipadora de luchas y de transformaciones colectivas en el marco de un proceso que va paso a paso, del "deseo de reforma y rebelión" en palabras de Harvey. 
Este abordaje desde el cuerpo conduce a la comprensión del territorio desde otros escenarios. Por ejemplo, desde el análisis social de los impulsos, los afectos, las fuerzas reactivas que intervienen en la circulación del capital variable durante la producción, el intercambio y el consumo individual. En el aula escolar evidenciamos la importancia de ese intercambio colectivo que interviene en experiencias colectivas.

Retomando lo dicho, en el mundo contemporáneo el desarrollo social suele ser entendido desde hace décadas meramente como una evolución técnica e industrial dentro de una desigual estructura internacional de factores productivos (Salort, 2012), sin embargo existen otras nociones como las de Amartya Sen, las cuales se centran en la importancia del desarrollo humano: un desarrollo humano sin los imaginarios autóctonos y, por tanto, sin la forma en la cual estos se relacionan con la naturaleza y con sus elementos (por ejemplo, con el agua). Es decir, se trata de un desarrollo planteado desde unos esquemas muy determinados de entender el mundo y la modernidad, que se internalizan mediante la colonialidad interna (Sousa, 2010). Este es un asunto que se torna complejo si se plantea la posibilidad de que la modernidad busque apropiarse, excluir y expulsar lo que es distinto, a la vez que suele imponer un régimen nacional monocultural y eurocentrista (Mignolo, 2010; Acosta, 2015).

En necesario tener en cuenta que la identidad étnica requiere de la territorialidad y la apropiación de espacios físicos. Pues bien, el espacio físico y la territorialidad a la que nos referimos en el presente artículo es específicamente el emplazamiento geográfico del municipio de Soacha, en Colombia, y la identidad étnica a la que se hace alusión, teniendo en cuenta que el espacio no solo es físico sino simbólico, es la identidad muisca, (el pueblo autóctono de dicho espacio geográfico). En torno al territorio, Montañez y Delgado (1998), sostienen que el análisis del mismo es indispensable para la comprensión de la formación socio-espacial de un país o región y para la construcción de objetivos comunes nacionales que orienten los proyectos colectivos a futuro. De esa forma, para dichos autores:

- El cuerpo como territorio es una categoría que nos invita a pensarnos el aula desde las diferentes experiencias para la comprensión y apropiación del territorio.

- El territorio es un espacio de poder que se expresa en la gobernabilidad, la gestión y el dominio estatal, es un espacio de individuos, de grupos y organizaciones y empresas locales, nacionales y multinacionales.

- La actividad espacial de los agentes sociales es diferencial y sus prácticas se actualizan constantemente. Partiendo de ahí, la capacidad real y potencial de estos agentes de crear, re-crear y de apropiarse del territorio no es igual para todos.

- En el espacio concurren y se sobreponen distintas territorialidades locales, regionales, nacionales y mundiales (para el caso que se estudia se habla, por ejemplo, de identidad suachuna). Estas identidades poseen intereses distintos, con percepciones, valoraciones y actitudes territoriales diferentes que generan a su vez relaciones de complementación, de cooperación y de conflicto.

- El territorio no es fijo y estático, sino móvil, dinámico, mutable y desequilibrado. La realidad geosocial es cambiante y requiere permanentemente nuevas formas de organización territorial. Si se hace un breve análisis acerca de qué tanto se ha visto modificado el territorio suachuno, se puede afirmar que cada año las transformaciones son evidentes. Se destaca especialmente el relieve, visiblemente cambiante por la actividad minera, de manera legal e ilegal ante la mirada de las autoridades y en la lucha de organizaciones ambientales, que se realiza en zonas muy cercanas a áreas de vivienda, sobre montañas sagradas muiscas, en un ecosistema de páramo que es invaluable, tanto desde la perspectiva de la cosmovisión ancestral, como desde la importancia ecológica de un ecosistema 
como este, pues es el nicho de muchas especies que van de la mano a los diferentes procesos tanto biológicos como sociales, por ser fuente de vida y de agua.

- Los sentidos de pertenencia e identidad, de conciencia regional, al igual que los de la ciudadanía y de acción ciudadana, sólo adquieren existencia real a partir de su expresión de territorialidad (Montañez y Delgado, 1998). Lo cual puede evidenciarse en esa preocupación de los diferentes actores de la región, el sentir de protección, de identificar unas problemáticas que van ligadas con dicho territorio, el proponer acciones que puedan mover a la ciudadanía y que sea motor de cambio, el ejercer presión sobre las entidades gubernamentales para que se generen movimientos y/o acciones que aporten de manera positiva a la conservación y preservación de lo propio.

De lo anterior se puede concluir que en Colombia se sobreponen múltiples territorialidades y con ellas múltiples formas de identidad e incluso de nacionalidad, es decir, existe un entramado de plurinacionalidad ocultado por las formas en las cuales opera la modernidad y sus expresiones monoculturales (Acosta, 2015). Por ello mismo es necesario, en pro de reconocer la importancia de la diversidad humana y de las múltiples visiones y cosmologías que la pueden enriquecer, vislumbrar el territorio y las formas de vivirlo como maneras en las cuales se puede abogar por dicha diversidad. Resumiendo lo expuesto hasta este punto, se puede decir que el territorio se define tal y como se lleve a cabo en las prácticas y en los imaginarios de los distintos grupos sociales. Se dice, entonces, territorio en términos de las visiones ancestrales y los grupos autóctonos. O podemos decir incluso espacio, término empleado por Lefebvre (1974),quien sostiene que:

(...) todo lo relacionado con el espacio; por ejemplo, la construcción, la urbanización, las inversiones en este terreno, la venta y la compra del espacio como totalidad y la especulación, por supuesto. Esta importancia es desigual según los países. Hay países en los que todo lo que concierne a estos aspectos se convierte en el sector principal de la economía, hay países en los que simplemente es una polea, en otros países es todavía secundario (p. 220).

Es decir, aún en el mundo moderno industrializado la noción de espacio es variable y, peor aún, de acuerdo con Lefebvre (1974), está sometida a las fuerzas del mercado y la especulación. De ahí que en el capitalismo, según dicho autor, sea imposible hacer una planificación espacial en términos netamente humanos. Entonces, en este contexto, las visiones del territorio que tienen las comunidades autóctonas desde sus visiones ancestrales pueden ayudar a dotar de humanidad y sentido pleno de derechos la forma en la cual se concibe y se apropia el territorio.

En otras palabras, para el caso de la pedagogía muiskanoba, se intenta construir una identidad territorial regional sustentada en el rescate de la ancestralidad muisca, para la cual la misma práctica de recorrer el territorio a manera de ritual es una forma de apropiarse socialmente del mismo. Para abordar mejor este punto, en el apartado siguiente se contextualizará el municipio de Suacha y se relacionará el tema del territorio con otras formas de entender el espacio, desde la perspectiva económica e incluso con el cuerpo entendido como espacio. Y más importante aún, se relacionarán el territorio con las experiencias de los estudiantes del colegio "Bachillerato tecnico comercial Santa Ana", a fin de responder a la pregunta planteada en la introducción.

\section{De las cartografías de la precariedad hacia las cartografías de las resistencias}

"Mi barrio antes de ser conocido como "el silo" era una caballerizas de sólo tierra y pasto"

Danna Delgado, estudiante grado séptimo, 2020 
Este apartado tiene como finalidad esbozar una lectura del municipio de Suacha desde la perspectiva de las cartografías de precariedad. Ya habíamos enunciado esto a modo de pregunta porque evidenciamos contradicciones al considerar al municipio como "precario", desde la dimensión humana y ecológica. Más bien, transitamos hacia unas cartografías de la resistencia, que enuncian el asumir las dinámicas sociales desde las oportunidades de su transformación, desde el campo de la educación que emancipa desde la marcada historia que lo envuelve.

Las cartografías de la resistencia se enuncian como posibilidad de contraponer al sistema económico neoliberal y hacerle frente al sistema patriarcal capitalista que ha priorizado el capital sobre la vida humana, la escuela se convierte en un escenario de debate y transformaciones que se articulan a las propuestas y luchas del movimiento social y feminista en el municipio de Suacha, esto de la mano con las reivindicaciones y procesos que se tejen en el municipio con otros actores sociales y políticos.

Las cartografías de la resistencia buscan la integración de los pueblos para esa otra América decolonial, antipatriarcal y anticapitalista, de acuerdo a la lectura de José Seoane \& Emilio Taddei (2005)

"La búsqueda de esa Otra América bajo la referencia de la integración de los pueblos habrá de tener en el ciclo de conflictos sociales, crisis politicas y transiciones que recorre parte de la reciente geografía regional su capitulo nacional. En este camino, la contundente expresión del pueblo que habita el territorio de Bolivia a favor de modificar la injusta matriz neoliberal -que signó la victoria electoral de Evo Morales- habrá de señalar nuevamente la vigencia de un horizonte alternativo para las sociedades latinoamericanas"

El municipio de Suacha se encuentra ubicado al sur de la ciudad de Bogotá, esta característica geográfica hace que sea un municipio fundamentalmente de recepción de población migrante. Esta es de dos tipos: migración voluntaria y desplazamiento forzado. La última se analiza desde la categoría de víctimas del conflicto armado colombiano, que desde los años 80 han habitado algunos de los barrios populares del municipio (Rodríguez, 2017, Garzón, Ramos \& Quintana 2015, Universidad Minuto de Dios, 2015, entre otros).

Estos flujos migratorios poblacionales auspician el intercambio cultural colectivo, a la vez que se relacionan variables económicas y políticas que se encuentran en el orden del manejo de los recursos públicos. Algunas personas llegaron a Suacha por las dinámicas de propiedad horizontal que se ha dado en los últimos 15 años, como lo menciona Edison Herrera de grado séptimo:10 "yo llegué a mi barrio porque hicieron un sorteo de este apartamento y mi mamá se ganó el apartamento y nos venimos a vivir acá".

A su vez el espacio rural se ha visto disminuido considerablemente por los procesos de expansión urbana, al respecto la estudiante Laura Pachón, de grado séptimo, ${ }^{11}$ menciona: "el territorio donde vivo antes correspondía a zonas rurales, pues era una hacienda grande con hermosos pastizales que alimentaban el ganado, había árboles y humedales, y mucha variación de aves que hacían parte del sector llamado "las huertas", también había pequeñas quebradas y una montaña muy grande declarada como reserva forestal, la cual sirve como mostrador del mirador".

Es así como Suacha presenta una gran contradicción: por un lado, es un territorio que riqueza cultural y humana, pero por el otro, es un municipio explotado, precarizado y desvalorizado por los múltiples actores regionales, tal como lo menciona Laura en con su relato: "en la actualidad he podido observar los grandes cambios que han ocurrido y el cambio ha sido radical, desapareció lo rural, ahora todo es urbanístico, hay

10 Trabajo en clase "historia de mi barrio" realizado por Edison Herrera del grado séptimo.

11 Trabajo en clase "historia de mi barrio" realizado por Laura Pachón del grado séptimo 
edificios y muchos conjuntos residenciales grandes, centros comerciales, incremento de población..."

En el campo educativo evidenciamos problemáticas relacionadas con la calidad y cobertura de los servicios educativos, se han explorado alternativas como la asignación de convenios con colegios públicos. El Colegio "Bachillerato técnico comercial Santa Ana" hace parte de esa prestación del servicio, donde sin lugar a dudas prima la garantía del derecho a la educación de los jóvenes y la transformación de la comunidad ante el respeto por la interculturalidad. Sin embargo, es importante aclarar que el sistema de contratación por medio de convenio también ha generado experiencias de corrupción en el municipio, cuestión que importante mencionar pues afecta a las familias que lo habitan.

Identificamos varios cuestionamientos en los procesos de aprendizaje de nuestros estudiantes, en los cuales se deben priorizar los espacios comunes y compartidos, desde los principios de la propuesta pedagógica muiskanoba. Esta propuesta de innovación pedagógica desde el sur, que como se presentó en el primer apartado, nos invita al reconocimiento de nuestras realidades personales y colectivas para la transformación social de estas, nos invitan al confluir, descubrir y compartir. Desde esta perspectiva, se incentiva a los estudiantes a explorar y reconocer el/su territorio desde diferentes dimensiones, una de ellas es: el cuerpo como territorio. En la siguiente Figura $\mathrm{N}^{\circ} 1$ se muestra la noción del cuerpo como forma de expresión social y simbólica que se comparte en un espacio social. En este caso, el aula de clase se convierte en el lugar donde se comparten expresiones artísticas que desdoblan el cuerpo, el alma y la mente.

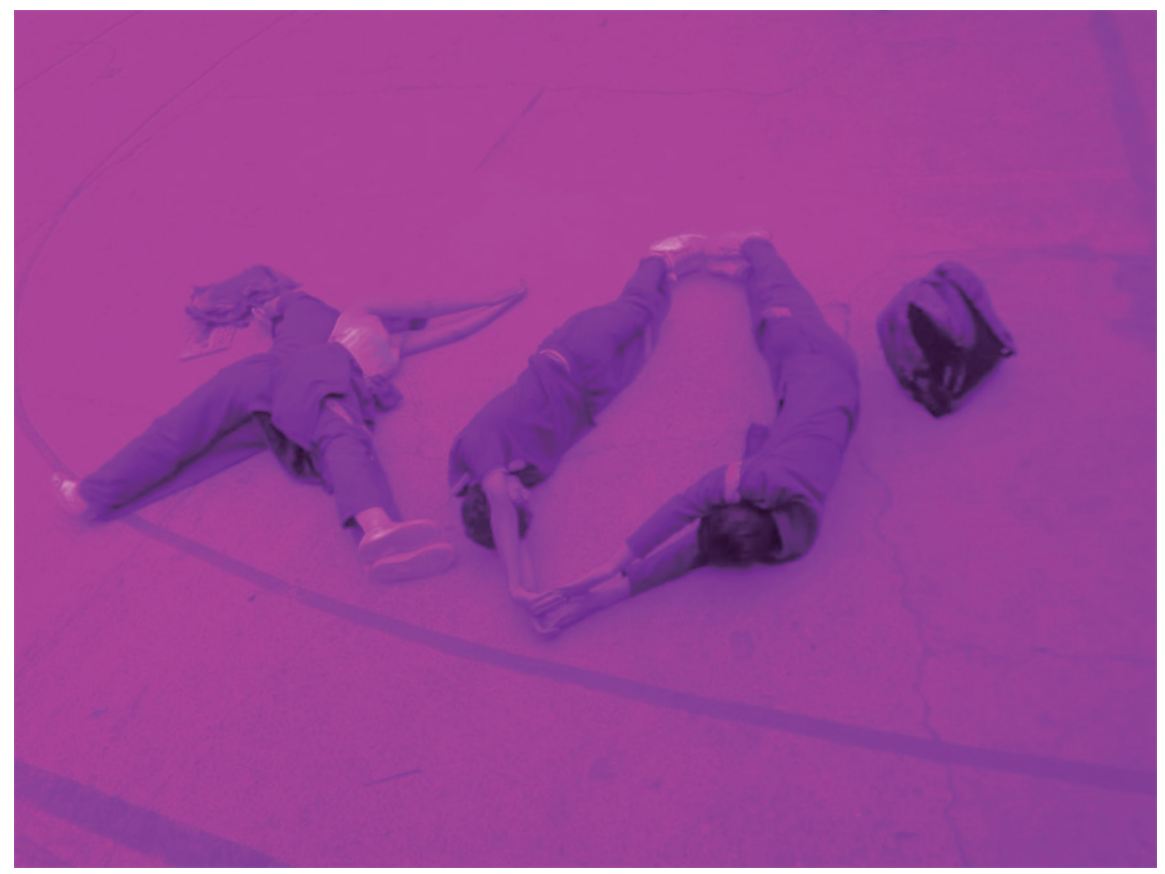

Figura $\mathbf{N}^{\circ} 1$ - El cuerpo como territorio

Autora: María Medina, estudiante grado noveno (2019). Archivo fotográfico, Galería muiskanoba.

Luego pasamos al espacio de mi compañero como el territorio cercano, en este territorio empezamos a comprender la dimensión colectiva del cuidado, del sentido y del tejido. Generamos imágenes simbólicas ${ }^{12}$ que nos invitan al cuidado del otro como si fuera lo propio. Al reconocer a un otro estamos invitando a la participación en el aula, que es el espacio de interacción directo de los estudiantes, con los maestros y viceversa.

12 El concepto de imágenes simbólicas refiere a la representación de formas comunes y cotidianas por una convención social establecida que es común para un grupo social. 
Comprendemos que la concepción de aula se encuentra enmarcada en relaciones de poder que se tejen en estos espacios colectivos.

Las relaciones de poder no deben estar mediatizadas por jerarquías sociales que propician identidades de las personas, sino que deben encontrarse abiertas al círculo de saberes que cada uno de nosotros puede compartir. Sin embargo, es evidente que forjar espacios de horizontalidad requiere autonomía y sensibilización colectiva, en ese camino estamos, los sabedores (docentes), administrativos, directivos, padres y madres de familia y estudiantes.

Una escala intermedia es el espacio-colegio donde se generan interacciones sociales y experiencias de vida importantes para la apropiación del territorio suachuno, en la Figura $\mathrm{N}^{\circ} 2$ nos lleva a un espacio íntimo del colegio, donde se encuentra la biblioteca y, al fondo, evidenciamos la relación estrecha con la naturaleza, puesto que en la imagen del mural es posible identificar a la madre tierra que regocija el agua y una hermosa flor, que se lleva toda la atención. Esta composición fotográfica nos lleva a reconocernos, que aunque nos encontremos en un espacio construido. No nos desprendemos de la naturaleza, que es nuestra fuente de conocimiento, de vida y de regocijo espiritual.

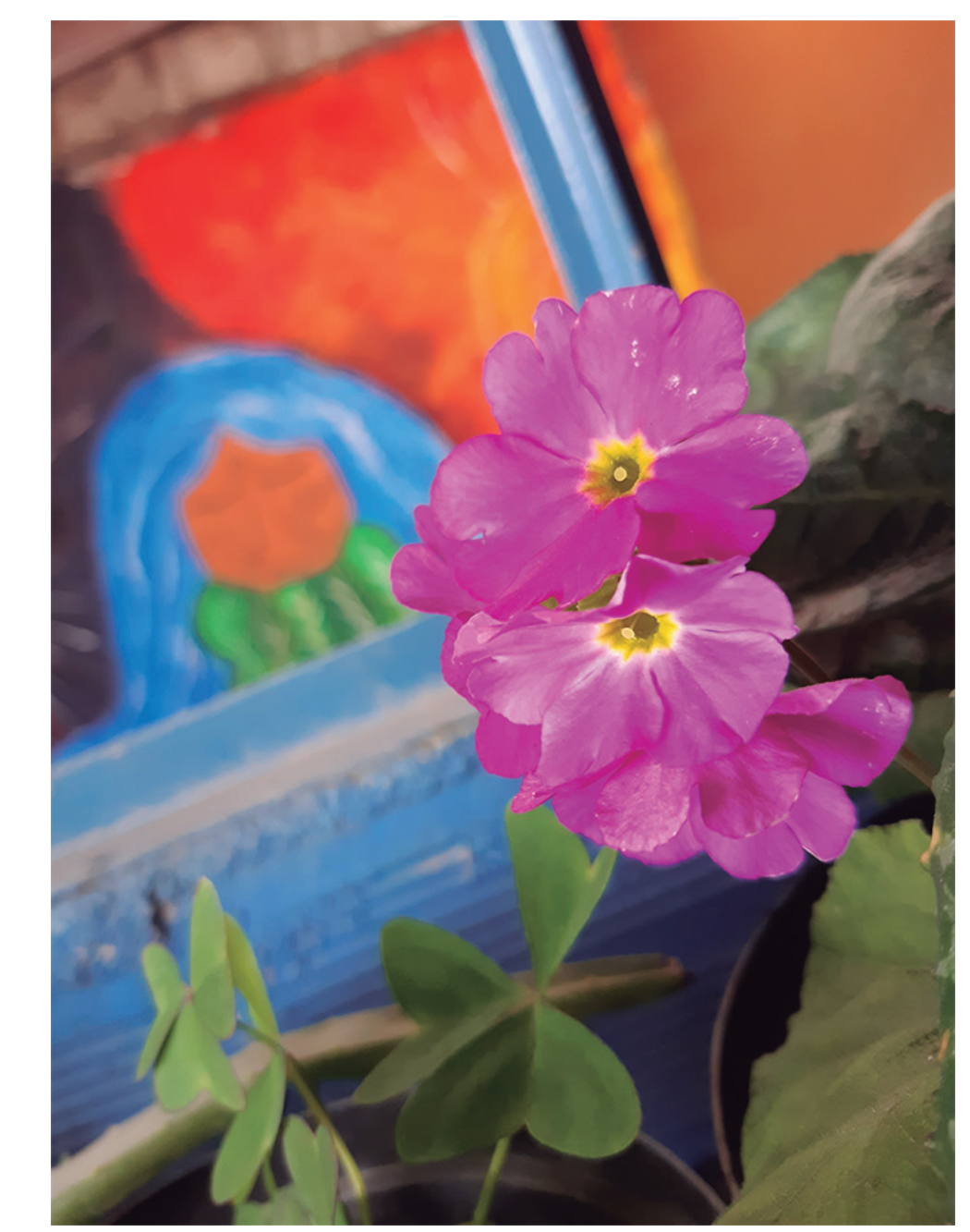

Figura $\mathbf{N}^{\circ} 2$ - Intimidad-es

Autor: Manuel Méndez, grado noveno (2019). Archivo fotográfico de la Galería Muiskanoba.

El siguiente territorio que recorremos es el territorio barrio, en él generamos procesos de reconocimiento con los estudiantes, articulando los procesos colectivos que se encuentran en los barrios. Samuel Bermeo, estudiante del Colegio ${ }^{13}$ menciona: 
"Y desde que tengo memoria mi barrio ha cambiado mucho, antes solo era un potrero y después la comunidad del barrio ayudó a poner unos parques para que los niños jueguen y que pasen el tiempo, pero lo más importante de mi barrio es que queda ubicado el humedal del neuta que pocos conocen y por eso lo están dañando, como los árboles que cortaron para construir el conjunto parque campestre".

Lo que evidencia el estudiante es la preocupación por el ecosistema "humedal del Neuta", un espacio que se encuentra en proceso de recuperación desde hace más de 30 años, desde donde se han generado procesos de recuperación ambiental como los gestores del agua (SETIS, 2019), humedal de alta importancia ecosistémica que alberga especies de flora y fauna nativa y endémica de Colombia. Luego de explorar el territorio barrio, recorrimos el territorio Suacha, un espacio para re-conocer nuestro municipio e identificar la riqueza ambiental y social en la cual nos encontramos.

También encontramos las duras realidades que viven las estudiantes en sus espacios, enunciación debe ser constante. El siguiente fragmento corresponde a Sharon Marulanda, de grado séptimo, quien quiso compartir sus impresiones sobre su barrio, que recoge sus cotidianidades. Vemos que los barrios son espacios de exclusión y problemáticas sociales y ambientales:

mmmm mi barrio ducales soacha ${ }^{14}$

-antes mi barrio era solo potrero

-antes mi barrio tenía zonas verdes

-antes mi barrio tenía lagunas limpias

-antes en mi barrio no botaban tanta basura

- antes en mi barrio dejaban salir a los niños a jugar

-ahora mi barrio tiene casas y no hay árboles

-ahora las zonas verdes la quitaron y eso es malo para el medio ambiente

-ahora las lagunas tienen basura y botan desechos

-ahora el barrio no se debe llamar ducales sino el basurero de soacha

-ahora los padres no dejan salir a los niños por las personas malas que cojieron el barrio de fumador y en el barrio los padres tienen miedo de las personas que secuestran y violan niñ@s y mi barrio por eso no tiene buena propaganda y por eso mi barrio se volvió uno de los lugares que son peores que el bronx, se que exagero pero en lo que a mi concierne ducales a cambiado mucho

Fin.

Otro relato que es importante mencionar es el de la memoria y los aprehendizajes compartidos. El siguiente relato fue escrito por Gabriel Albarracín, del grado séptimo, ${ }^{15}$ quien invita a la añoranza y a las memorias cotidianas:

La historia de mi barrio es un dia cuando mi papá y mamá tenían un negocio y nos iba muy bien. Un día mi papá dijo "nos trasteamos para SOACHA" y nos fuimos a ese lugar. Era muy chebre hay viví toda mi infancia y aprendi que es el trompo, las canicas, álbumes y cartas pasaron 7 años y me trastie para VENECIA y soy muy feliz aquí pero si extraño a todos mis amigos que vivían en SOACHA.

En cuanto a las representaciones de los estudiantes sobre el municipio, es importante trabajar los imaginarios que se generan, pues los medios de comunicación se han 14 Trabajo en clase "historia de mi barrio" de Sharon Marulanda, del grado séptimo. 15 Trabajo en clase "historia de mi barrio" de Gabriel Albarracínl del grado séptimo. 
encargado de desprestigiar el municipio, resaltando los aspectos problemáticos (como el hurto, los migrantes, la pobreza extrema, la congestión en el Transmilenio y demás características que hacen que se generen imaginarios negativos en nuestros estudiantes). Sin embargo, desde la pedagogía muiskanoba se busca resaltar los aspectos positivos y la esencia ancestral del territorio del municipio, sin desentendernos de las problemáticas en las que diariamente convivimos que finalmente nos guia para a la innovación social y educativa.

Este trabajo continúa siendo un reto para la comunidad educativa puesto que las representaciones sociales de nuestro territorio se deben transformar en acciones que propendan por el cambio y la transformación hacia un espacio territorial más ameno y consciente de la riqueza ambiental y ancestralidad muisca que posee. En la Figura $\mathrm{N}^{\circ} 2$ se evidencia los espacios hídricos, los espacios históricos, los lugares que hacen feliz a la estudiante Sammay y los lugares que le dan temor.

Estos procesos de sensibilización con los estudiantes han sido un trabajo que se prioriza desde las itinerancias, ${ }^{16}$ puesto que identificamos la necesidad de generar apropiación social del municipio, articulados a los diferentes actores territoriales que lo componen.

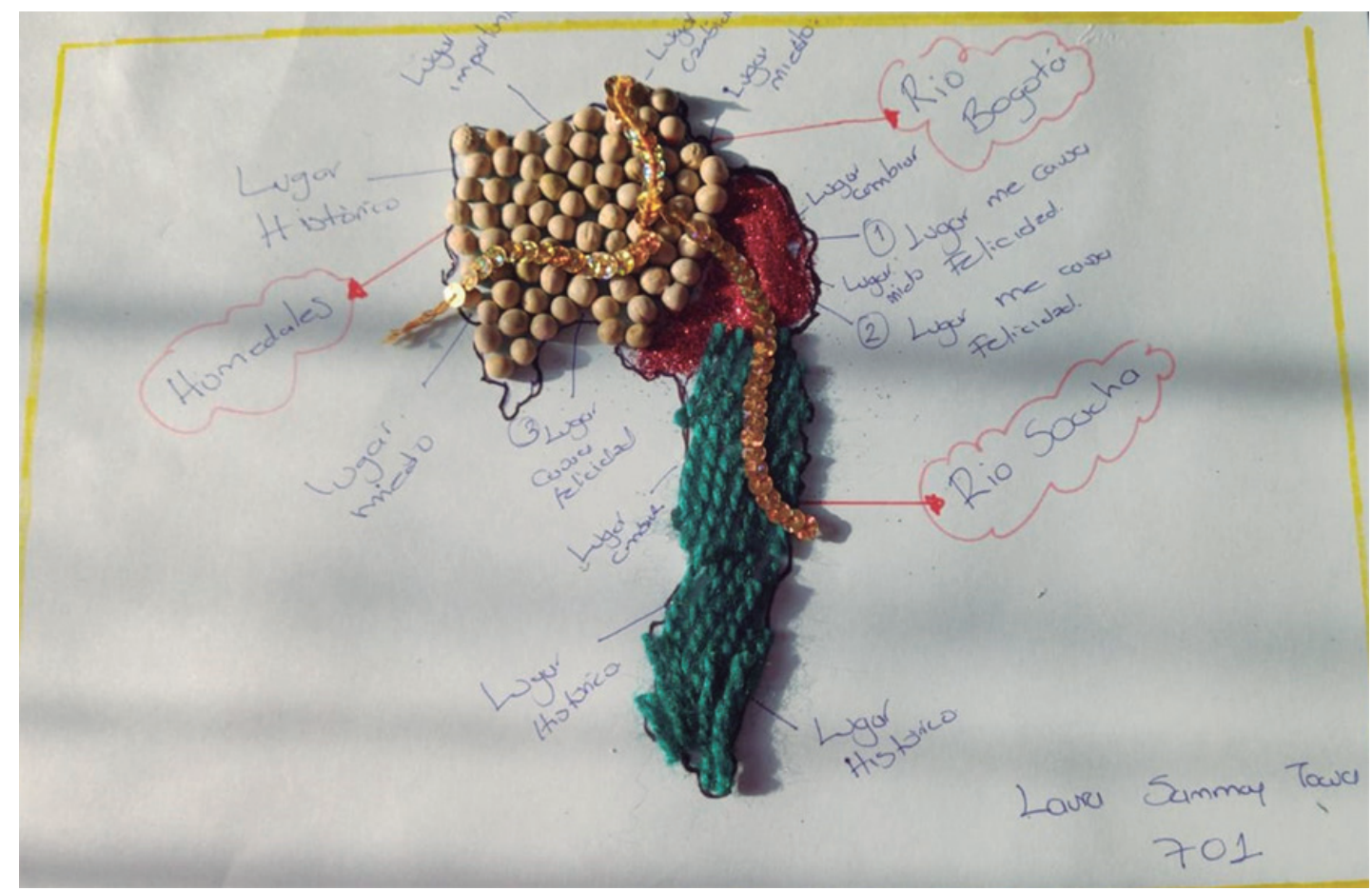

Figura $N^{\circ} 3$ - Suacha, lugares y memorias

Autora: Sammay Tocua, grado séptimo (2020), Cartografía de Suacha.

\section{Las organizaciones sociales y el trabajo colectivo}

La articulación con las organizaciones sociales ${ }^{17}$ que reconocen y defienden el territorio es fundamental puesto que son ellas las que se encuentran en el día a día con las complejas problemáticas del municipio. Los maestros del colegio "Bachillerato técnico comercial Santa Ana", desde nuestras herramientas pedagógicas y políticas,

16 Itinerancia refiere a recorrer las diferentes dimensiones del territorio, una de las principales características de la metodología didáctica del colegio.

17 En este apartado se mencionan algunas experiencias, por motivos de espacio no es posible relacionarlas todas. Sin embargo, agradecemos el acompañamiento de FINCONPAZ, el servicio Jesuita de Refugiados, Suacha Conexión, Caminando el territorio, La fundación Frans Brüggen y demás organizaciones que nos han acompañado en el proceso formativo para nuestra comunidad. 
incentivamos la participación de otros actores territoriales, pues son ellos quienes conocen y auspician procesos de transformación social en otros espacios, animando a el compartir de saberes desde lo propio, llevando al aula el contexto local, priorizado ante los conceptos fríos de occidente.

Las Organizaciones ambientales han sido muy importantes en esta labor por la defensa, conservación y preservación del medio de vida que habitamos. Organizaciones como Caminando el Territorio ${ }^{18}$ se ha articulado de manera investigativa y social a los procesos que se han trabajado, como la investigación de la Sie $e^{19}$ (Agua), en el municipio. Esta consiste en valorar, significar y re-significar el uso del agua en lo cotidiano: en las clases de química, física, biología y medio ambiente, pero también comprender que ha sido el recurso cohesiónate de las primeras comunidades y dialogar sobre el entendimiento del agua desde una perspectiva filosófica e investigativa que nos permite ese diálogo inter- epistémico entre la química y biología occidental y el itinerar/describir de la propuesta de innovación pedagógica muiskanoba para el reconocimiento del territorio y las riquezas hídricas del municipio.

La organización Semillas de la tierra y el $\mathrm{sol}^{20}$ es una organización ambiental que se encuentra trabajando en el humedal del Neuta, que como se mencionó anteriormente, ha realizado un proceso de recuperación socioambiental, el cual ha profundizado en la integración de la comunidad en el manejo, conservación y preservación del humedal. Los estudiantes se han articulado a este proceso como gestores sociales y han generado aprendizajes desde la perspectiva práctica.

Con la Universidad Minuto de Dios sede Suacha se ha articulado esfuerzos para la participación en la emisora institucional en la plataforma virtual de dicha universidad. Esta ha sido una experiencia enriquecedora desde la formación integral, pues explora aspectos como trabajo en equipo, investigación, elaboración de discursos y exposición de ideas, que desde un punto de vista pedagógico aporta significativamente en los estudiantes, familias, radioescuchas y sabedores participantes.

Además, desde lo comunicativo se ha querido profundizar el uso de la imagen como expresión y como herramientas que transmite ideas, sentimientos, mensajes y, en últimas, percepciones de nosotros mismos. Con la Corporación Suacha Conexión ${ }^{21}$ se implementó un proceso desde la metodología de formación en proyectos, que tuvo como objetivo principal propiciar un espacio de formación teórico práctica en fotografía e imagen con el fin de reconocer su espacio territorial próximo (el colegio), reconociendo la imagen también como expresión artística.

Desde los diálogos generados en este proceso con Katherine Ramírez, gestora de Suacha conexión, amiga y compañera del proyecto "Luminiscencias", menciona:

El proyecto de formación en comunicación "Luminiscencias" que se realizó en el colegio Santa Ana hace parte del marco del Plan Estratégico Territorial y es liderado puntualmente por la organización Suacha Conexión. Esta iniciativa tuvo resultados muy positivos, tanto para los jóvenes como para la organización. Desde mi percepción, la organización tuvo la oportunidad de poner a prueba la metodología creada, generar una alianza con la institución y un vínculo con los jóvenes participantes. Para mí, fue satisfactorio ver que los jóvenes eran participativos y generaban ideas. Otro dato que facilitó el trabajo, es que

18 Es una organización social dedicada a la defensa y preservación de los aspectos ambientales del municipio de Suacha. Ver página web para mayor información: https://caminandoelterritorioblog.wordpress.com/

19 Concepto muisca para designar al agua, la diosa del agua.

20 Es una corporación que actualmente está trabajando en el municipio de Suacha, protegiendo los recursos naturales y la preservación de los ecosistemas de los humedales Neuta y El Vínculo. Para mayor información ver página en facebook: https://www.facebook.com/CORPOSETIS/

21Es una organización que se ha dedicado al trabajo comunitario de la Comuna 1, llamada Compartir, en el Municipio de Suacha. Su enfoque son las comunicaciones y la producción de imagen, también realizan trabajo con jóvenes y mujeres, desde una perspectiva de transitar memorias y de género, ver página web para mayor información: http://www.suachaconexion.com/. 
varios de ellos tienen de manera cercana los conceptos de identidad y sentido de pertenencia (gracias a la institución a la que pertenecen), lo que ayudó a que la organización pudiera enfocarse más en los aspectos teóricos y prácticos del arte audiovisual (Comunicación personal, 31/03/20)

El resultado de ello fue una galería fotográfica que se expuso el año pasado (2019),de autoría de los estudiantes, la cual evocó compañerismo, solidaridad, momentos vividos, imágenes y objetos cotidianos desde diferentes tonos y matices, donde se evidenció el sentido de pertenencia, en su composición fotográfica, que menciona Katherine. En el siguiente espacio se comparten algunas fotografías.

En la Figura $N^{\circ} 3$ se identifica a la imagen del dios varón con los colores del arcoíris, lo que significa diversidad y respeto por la orientación sexual, mural diseñado por la personera del año 2019 Karol Ballesteros. Es en este proceso de largo aliento se ha incentivado el reconocimiento por el otro desde la diversidad y la pluralidad de pensamientos, acciones, identidades de género o expresiones culturales. En este sentido, convergemos con la participación amplia de todas las formas de ser/sentir, pues es así como nuestros abuelos, quienes hacen parte del legado, enseñan el respeto por el otro desde su diferencia.

Lo anterior expone de manera sintética algunas acciones que se han llevado a cabo en el espacio escolar, nos quedan muchas historias por compartir. En el siguiente apartado se comentarán algunas reflexiones propias.

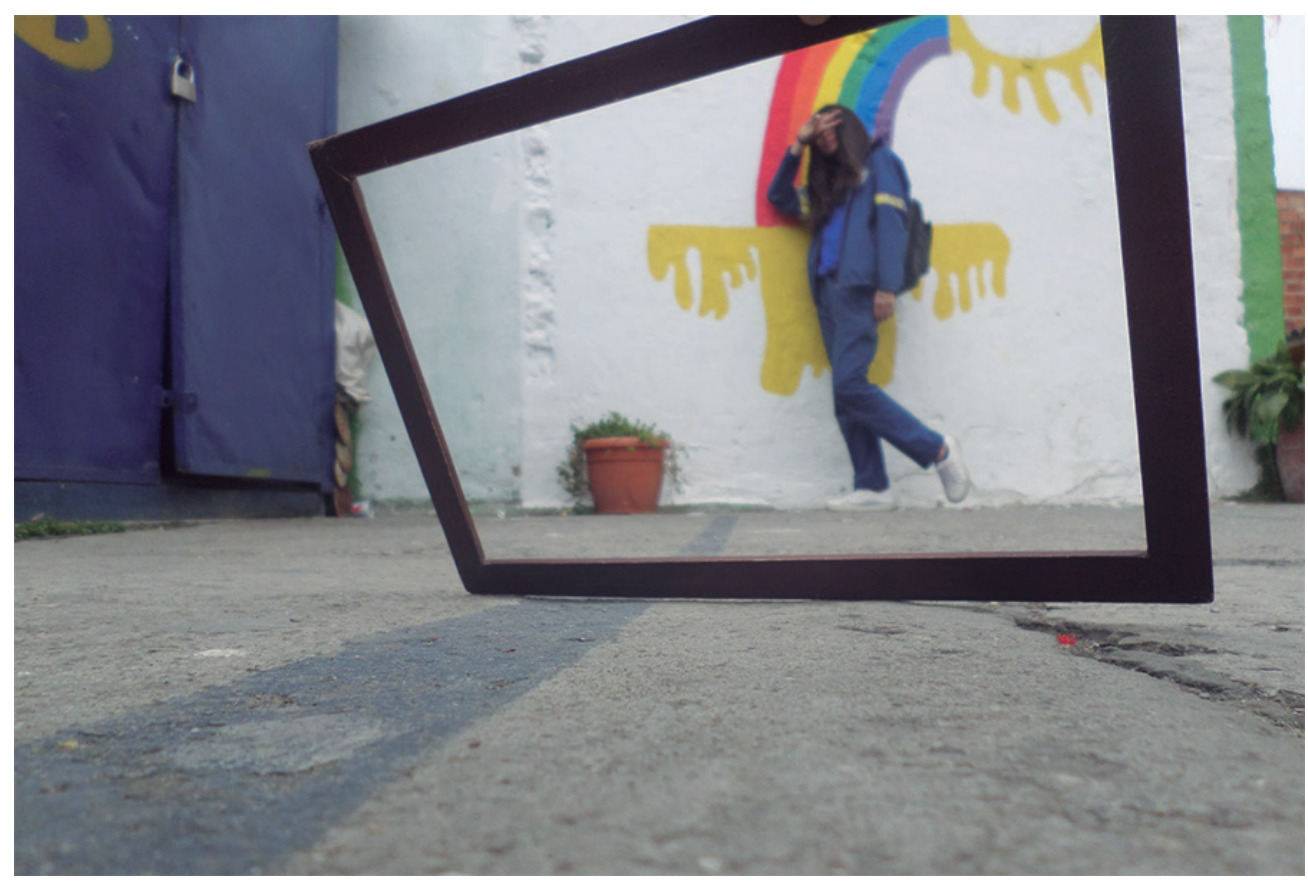

Figura $\mathbf{N}^{\circ} \mathbf{4}$ - Momento relax

Autora: Laura Pava grado noveno (2019). Archivo fotográfico de la Galería Muiskanoba.

\section{El espacio social como dialéctica feminista, anticapitalista y decolonial}

Occidente/la civilización y América/la barbarie

Karina Bidaseca (2014)

Luego de explorar las dimensiones del territorio, en donde evocamos sentimientos, memorias, y procesos pedagógicos, en el apartado anterior se contaron algunas experiencias que se han realizado de la mano de algunas organizaciones sociales que han apoyado el proceso. En este sentido, es fundamental articular 
acciones con la comunidad educativa, es decir, la escuela no puede ser un espacio aislado de la realidad social. La comunidad educativa debe estar articulada a estos procesos.

Desde la pedagogía muiskanoba se ha propuesto llevar a cabo la metáfora del tejido, desde las puntadas generar nudos que alimenten los esfuerzos de los docentes, padres de familia, directivos, estudiantes y egresados. Es necesario cuestionar las dinámicas monótonas y excluyentes que se encuentran a nuestro alrededor y tejer otras formas de relacionamiento humano y colectivo, que tengan presente las múltiples dimensiones del contemplar, describir y compartir.

Este ha sido un camino largo que nos ha llevado a múltiples contradicciones y retos tanto personales como colectivos. El espacio social no es neutral y obedece a una serie de dinámicas, citamos las que menciona Osorio (2013):

A la par, se asignan espacios sociales a cada identidad genérica que se sitúan en lugares concretos, determinados por fronteras simbólicas, materiales e históricas que corresponden a un orden social y jerárquico. En ello reside la importancia del análisis urbano arquitectónico, ya que es un área que reproduce la estructura social de dominación a través del diseño y construcción de espacios como la vivienda" ( $p .113)$.

En el contexto del colegio priorizamos que las experiencias se encuentren resignificados, que existan apropiaciones que reivindiquen los saberes ancestrales, femeninos y sagrados, así como nuestros indígenas reivindican lo femenino como una forma de acercarse a lo sagrado. Entender que el espacio social se encuentra mediatizado por relaciones de poder lleva a replantear estrategias pedagógicas que permitan miradas críticas, diferentes perspectivas y transformaciones desde las memorias cotidianas.

Cuando hablamos de dialécticas del espacio hacemos alusión a las múltiples formas en que podemos reivindicar la realidad social desde una perspectiva feminista, entendiendo que lo personal es político y que las pequeñas acciones hacemos política constantemente; es decolonial porque nos invita a pensarnos de maneras diferentes a las enseñadas por los colonizadores; es anticapitalista porque busca desprenderse de las lógicas económicas que han expropiado los espacios naturales para la mercantilización de la vida. Entonces, en estas tres concepciones entendemos que las transformaciones pedagógicas se tejen de manera horizontal, permanente y de largo alcance.

La historia de nuestros pueblos latinoamericanos ha sido una historia de pugnas por el poder político y económico, en ellas nos encontramos inmersos. Sin embargo, cuando conocemos y regocijamos nuestras mentes con espacios arqueológicos como pictogramas o gráficas, que nos invitan a reconocernos desde el interior, comprendemos que tenemos la capacidad de cambiar nuestro mundo, iniciando por nosotros mismos.

No podemos entender los espacios desde una dimensión exclusivamente física, existen espacios sociales y simbólicos delimitados que se encuentran al interior de nosotros y nosotras como formas y fuentes de saber, estos deben explorarse progresivamente. El saber no se encuentra en un grupo o una persona en específico (en este caso el maestro), sino que es necesario valorar el saber que tienen los estudiantes, quienes nos enseñan sus formas de comprensión y sus realidades inmediatas.

La Figura $N^{\circ} 5$ evoca a la diosa Bachué y su importancia como representación icónica y feminista en la institución. 


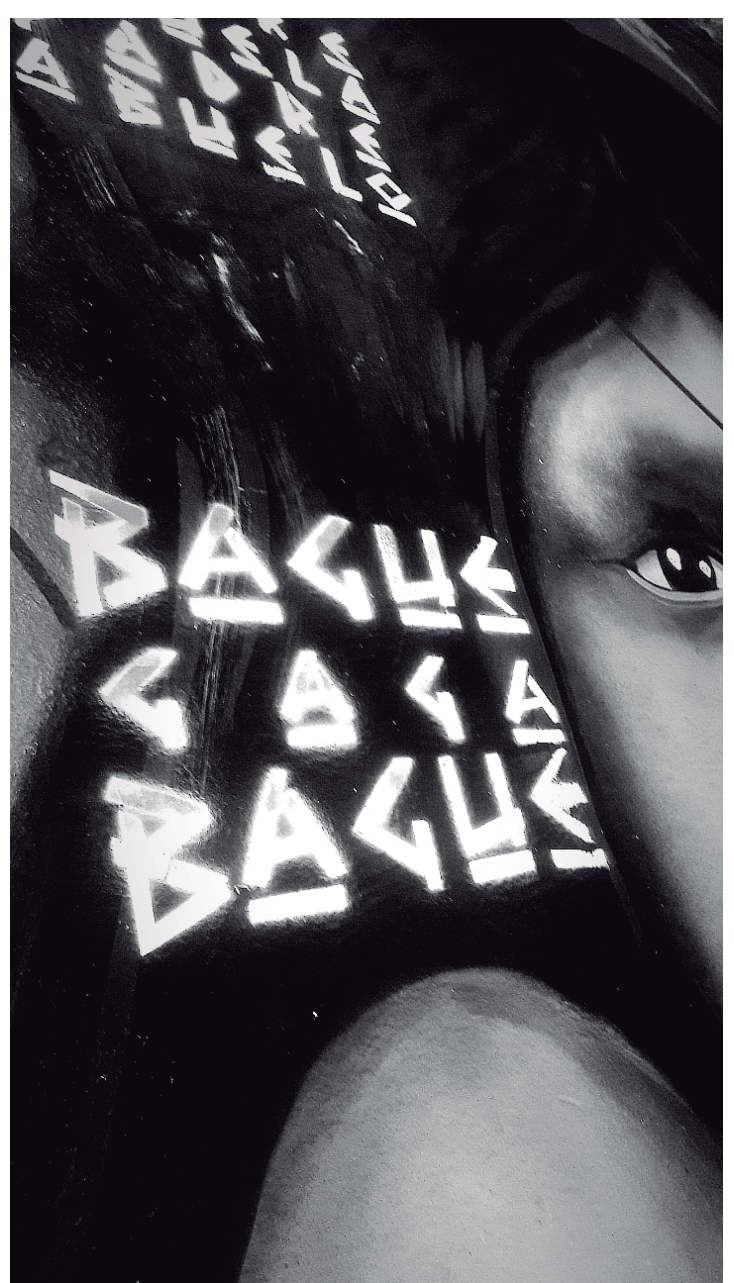

Figura N5 - Diosa Bachué

Autora: Zharick Salgado, grado noveno (2019). Archivo fotográfico de la Galería muiskanoba.

\section{Reflexiones Finales}

El presente artículo tuvo como finalidad reflexionar acerca de la experiencia pedagógica, sobre la categoría de producción del espacio social, desde algunos procesos que se han llevado a cabo en el "Bachillerato Técnico Comercial Santa Ana". Quisimos abordar también, cómo se construye y se vive en el colegio desde la propuesta de innovación pedagógica muiskanoba.

La pedagogía muiskanoba busca incentivar la apropiación social del territorio suachuno desde las aulas de clases. Estas tienen forma de círculo, lo que permite recorrer una y otra vez los mismos lugares para quedarse en ese andar común siempre y ver más allá que las pisadas que ya se dejaron, volver a recorrerlas cuantas veces sea necesario.

Se ha analizado cómo esas tradiciones ancestrales inspiran formas de apropiación social del territorio. Una de esas formas de apropiación la podemos hallar en la pedagogía que estructura la enseñanza en el colegio "Bachillerato Técnico Comercial Santa Ana" puesto que en la institución se maneja una pedagogía educativa propia, que hunde sus raíces en la cosmovisión de los grupos muiscas que ya habitaban el territorio del municipio de Suacha en Colombia para las épocas precolombinas.

Desde las cartografías de la resistencia se quiere invitar a continuar con el trabajo pedagógico, formativo y social que se ha realizado desde múltiples esfuerzos. Reconocemos no sólo desde la experiencia que se presenta aquí, sino toda la integralidad que como equipo docente y comunidad educativa han desrrollado, desde nuestros saberes, prácticas, sentires y retos para la formación en el siglo XXI. Por ello, 
agradecemos el trabajo de la comunidad educativa, que cotidianamente se esfuerza por mejorar no sólo la experiencia compartida de los estudiantes sino articular esfuerzos para generar identidad y apropiación social del municipio de Suacha desde una perspectiva decolonial, anticapitalista y antipatriarcal. Aún nos queda camino por recorrer.

Transitar por las nociones de cuerpo, barrio y territorio nos amplia un panorama de discusiones y debates que muchos autores han trabajado desde el punto de vista teórico. Sin embargo, habitar desde el sentir del tejido de los niños y las niñas con sus padres y familias nos motiva a descubrir la historia de Suacha desde el corazón, como decía Orlando Fals Borda: sentipensar la razón.

Finalmente, esta propuesta muiskanoba continúa en construcción de nuevas formas, aportes, tejidos y procesos que iniciando por la planeación de todos los sabedores que invitan desde el aula a generar el diálogo entre los saberes, representado de manera metafórica por la relación del territorio con la tierra para la siembra, iniciando el arado: deshierbando la maleza y moviendo la tierra con las manos, la siembra: poniendo esa mejor semilla para el cultivo, provista de agua, sol y cuidado, finalizando con la cosecha: el recoger los frutos para el compartir de las familias, así se gesta la labor educativa como propuesta de innovación del colegio Bachillerato Tecnico Comercial Santa Ana, sembrando en comunidad, con amor y paciencia. Se vienen nuevos retos por asumir y un cúmulo de experiencias por recordar y llevar a la memoria. Sin duda se busca la emancipación desde el aporte al desarrollo de la interculturalidad crítica para el buen vivir de la abya yala, la autocrítica, el aprehender y desaprehender, el compartir conjunto, para habitar al municipio de Suacha con orgullo y merecimiento.

\section{Bibliografía}

Acosta, Y. (2015). Emergencias de la trans-modernidad y refundación plurinacional e intercultural del estado: ecuador y Bolivia en el siglo XX1. Historia Actual Online, 37 (2), 2015: 85-100.

Bidaseca, Karina (2014). Cartografías decoloniales de los feminismos del sur. Apresentação. Revista Estudos Feministas, 22(2) ,585-591. [Fecha de Consulta 14 de Junio de 2020]. ISSN: 0104-026X. Disponible en: https://www.redalyc.org/articulo.oa?id=381/38131661011

Concha, M. (2007). Lucha por la dignidad y los derechos humanos individuales y colectivos de los pueblos de América Latina. Responsabilidad histórica: preguntas del nuevo al viejo mundo / coord. Por Gustavo Gutiérrez, 2007, págs. 313-332.

Cora Garcia, A. (2013). An Introduction to Interaction: Understanding Talk in Formal and Informal Settings. Bloomsbury, 2013. ISBN 9781441157614.

Corporación Universitaria Minuto de Dios- Regional Soacha (2015). Realidades territoriales en Soacha. Análisis de la vida cotidiana. Facultad de psicología.

Cuervo, Fernando. (2014). Latá-Latá. Buscando paz en las raíces. En Porras Contreras, Y. Retos y oportunidades de la educación ambiental en el Siglo XXI. Bogotá: Universidad Pedagógica Nacional- CIUP.

Dussel, Enrique (2014). 16 Tesis de economía política. Interpretación filosófica, México D.F., Siglo XXI, 424 págs.

Enríquez Martínez, A. (2007). La significación en la cultura: concepto base para el aprendizaje organizacional. Univ. Psychol. Bogotá (Colombia) 6 (1): 155-162, enero-abril de 2007.

Hinestroza Cuesta, L. y Guerrero Pino, S. (2017). El derecho humano a la propiedad colectiva de las comunidades negras en Colombia. Elementos para la construcción de una línea jurisprudencial. Justicia Juris, ISSN-e 1692-8571, Vol. 13, № . 1, 2017 (Ejemplar dedicado a: Enero - Junio), págs. 27-39.

Lefebvre, H. (1974). La producción del espacio. Artículo publicado en Papers, Revista de sociología, Núm. 3. (p. 219-229) 
Mignolo, W. (2010). La colonialidad: la cara oculta de la modernidad, En: Mignolo, W, Desobediencia epistémica. Retórica de la modernidad, lógica de la colonialidad y gramática de la descolonialidad. Buenos Aires: Ediciones del Signo.

Montañez Gómez, G. y Delgado Mahecha O. (1998). Espacio, territorio y región: conceptos básicos para un proyecto nacional. Cuadernos de Geografía, Vol. VII, No. 1 -2, 1998.

Osorio, L. (2013). Entre divisiones: género y espacialidad. Bitácora arquitectura + número 33, pág 113- 117. Universidad Autónoma de México.

Ortíz Ibañez, L. (2019). Narrando el tejido intercultural del territorio muisca de Bosa. Dirigida por Margoth Guzmán Monar (dir. tes.). Universidad Distrital Francisco José de Caldas (2019)

Panqueba, J. \& Huérfano, J. (2006). Muiskanoba: Territorios de aprendizajes para cotidianidades interculturales. Bogotá. Tesis de Maestría

Rodríguez Salgado, C. (2001). Los Derechos Humanos en América Latina: Por qué, para qué y para quién. Psicología desde el Caribe: revista del Programa de Psicología de la Universidad del Norte, ISSN 0123-417X, №. 8, 2001, págs. 53-62.

Rodríguez Silva,F.A.(2017).Del poblamiento prehispánico al modelo territorial colonial en el Municipio de Soacha, Cundinamarca: reflexión geohistórica de su configuración socioespacial. Perspectiva Geográfica, 22(1), 69-88. doi: 10.19053/01233769.6112

Salort Vives, S. (2012). Revoluciones industriales, trabajo y estado del bienestar: la gran ruptura mundial contemporánea. Madrid: Sílex.

Seoane José \& Tadei Emilio (2006). Cartografía de las resistencias y desafíos de la Otra América posible. En publicación: OSAL Observatorio Social de América Latina año VI, Número 18 CLACSO Consejo Latinoamericano de Ciencias Sociales, Buenos Aires Argentina.

Semillas de la tierra y el sol-SETIS- (2019). Gestores del agua en el humedal Neuta.

Stoller, P. (2009). Reconfigurar la cultura. Antípoda. Revista de Antropología y Arqueología. 2009; (8):12-31.

Sousa Santos, B. (2010). Descolonizar el saber, reinventar el poder. Montevideo: Ediciones Trilce.

Timm Hidalgo, A. K. (2017). Activismo judicial dialógico en América Latina: la lucha por los derechos. Tesis doctoral dirigida por Mario Giuseppe Losano (dir. tes.), Luis Manuel Lloredo Alix (codir. tes.), Carlos Lema Añón (tut. tes.). Universidad Carlos III de Madrid (2017). 